\title{
$f_{\max }$ and fault zone property of Lushan earthquake of 20 April 2013, Sichuan, China
}

\author{
Jian Wen • Xiaofei Chen
}

Received: 13 July 2013/Accepted: 12 September 2013/Published online: 30 October 2013

(C) The Seismological Society of China, Institute of Geophysics, China Earthquake Administration, and Springer-Verlag Berlin Heidelberg 2013

\begin{abstract}
In this study, we determined $f_{\max }$ from nearfield accelerograms of the Lushan earthquake of April 20, 2013 through spectra analysis. The result shows that the values of $f_{\max }$ derived from five different seismography stations are very close though these stations roughly span about $100 \mathrm{~km}$ along the strike. This implies that the cause of $f_{\max }$ is mainly the seismic source process rather than the site effect. Moreover, according to the source-cause model of Papageorgiou and Aki (Bull Seism Soc Am 73:693-722, 1983), we infer that the cohesive zone width of the rupture of the Lushan earthquake is about 204 with an uncertainty of $13 \mathrm{~m}$. We also find that there is a significant bulge between 30 and $45 \mathrm{~Hz}$ in the amplitude spectra of accelerograms of stations 51YAL and 51QLY, and we confirm that it is due to seismic waves' reverberation of the sedimentary soil layer beneath these stations.
\end{abstract}

Keywords Lushan earthquake $\cdot f_{\max } \cdot$ Strong ground motion · Fault-zone width $\cdot$ Cohesive zone

\section{Introduction}

The existence of $f_{\max }$ has been perennially observed in numerous earthquakes. According to the source-cause model by Papageorgiou and Aki (1983), $f_{\max }$ is caused by source processes and is inversely proportional to the linear size of the cohesive zone of fault rupture. As shown in

J. Wen $(\bowtie) \cdot X$. Chen

School of Earth \& Space Science, University of Science and

Technology of China, Hefei 230026, China

e-mail: wenj@ustc.edu.cn our recent study, such linear size of the cohesive zone happens to be the width of fault damage zone (Wen and Chen 2012). Fault-zone width of a ruptured fault is an important physical parameter for understanding earthquake rupture dynamics. The direct method of determining fault-zone width of an earthquake is through trapped waves experiment to collect seismic waves of either aftershocks or those generated by man-made active-source on the field survey lines crossing exposed fault traces at the surface (e.g., Li et al. 1994). Obviously, such direct method of determining fault-zone width only works for cases in which the ruptured fault is exposed at the surface: for example, the $1992 M_{\mathrm{w}} 7.3$ Landers earthquake, the $1995 M_{\mathrm{w}} 7.2$ Kobe earthquake, and the $2008 M_{\mathrm{w}} 7.9$ Wenchuan earthquake.

The $M_{\mathrm{s}} 7.0$ Lushan earthquake of April 20, 2013 occurred on a blind fault (Xu et al. 2013) and fault rupture did not extend to the surface as indicated by inverted kinematic source models (Zhang et al. 2013; Wang et al. 2013) and by geological field survey (Xu et al. 2013). Consequently, its fault-zone width could not be determined through the trapped waves experiment. Fortunately, some near-field strong ground motion data were recorded during this earthquake, which makes it possible to infer fault-zone width of Lushan earthquake by measuring $f_{\max }$ from the spectra of near-field seismic accelerograms as was done in our previous study of the Wenchuan earthquake (Wen and Chen 2012).

In this study, we will first show how to measure $f_{\text {max }}$ from the near-field seismic accelerograms of the $M_{\mathrm{s}} 7.0$ Lushan earthquake, and then to infer fault-zone width based on the source-cause model for $f_{\max }$. Finally, we will discuss the correlation of our results with those of the Wenchuan earthquake, and its implications for understanding of earthquake physics. 


\section{Measuring $f_{\max }$ from the near-field recorded accelerograms}

The near-field accelerograms of the Lushan earthquake we used in this study were provided by the China Strong Motion Network Center (Fig. 1). Each station of this network is equipped with a tri-axial force balance accelerometer (SLJ-100 type) which has a flat instrumental response from 0 to $50 \mathrm{~Hz}$ with a sampling rate of 200 samples/s. All records start at $20 \mathrm{~s}$ before the P-wave arrival. All the near-field stations we selected were deployed on soil sites.

According to Papageorgiou (1988), the spectra amplitude of an acceleration spectra can be modeled by the following formula:

$$
\mathrm{amp}=\frac{\Omega}{\left(1.0+\left(\frac{f_{\mathrm{c}}}{f}\right)^{p_{\text {low }}}\right)\left(1.0+\left(\frac{f}{f_{\text {max }}}\right)^{p_{\text {high }}}\right)}
$$

where, $f_{\mathrm{c}}$ is the corner frequency, $f_{\max }$ is the high-frequency cutoff beyond which the spectral amplitude decays dramatically. $p_{\text {low }}$ and $p_{\text {high }}$ are the exponents that control the slope of the spectrum below the corner frequency $f_{\mathrm{c}}$ and beyond the high-frequency cutoff, respectively as shown in Fig. 2. By fitting the spectra of accelerograms to formula (1), we can determine the $p_{\text {low }}, p_{\text {high }}, f_{\mathrm{c}}$, and $f_{\max }$ simultaneously. Before fitting the data, each accelerogram was first preprocessed by the baseline correction, removing instrumental response, detrending, and demeaning in time domain, and then it was transformed into the frequency domain. It was demonstrated in our recent study (Wen and Chen 2012) that the influence of the attenuation caused by quality factor $\mathrm{Q}$ in estimation of $f_{\max }$ is negligible. Moreover, influence of soil site effect on the variation of $f_{\max }$ is insignificant and is, for instance, less than $0.5 \mathrm{~Hz}$ for the Wenchuan earthquake (Wen and Chen 2012). Therefore, in

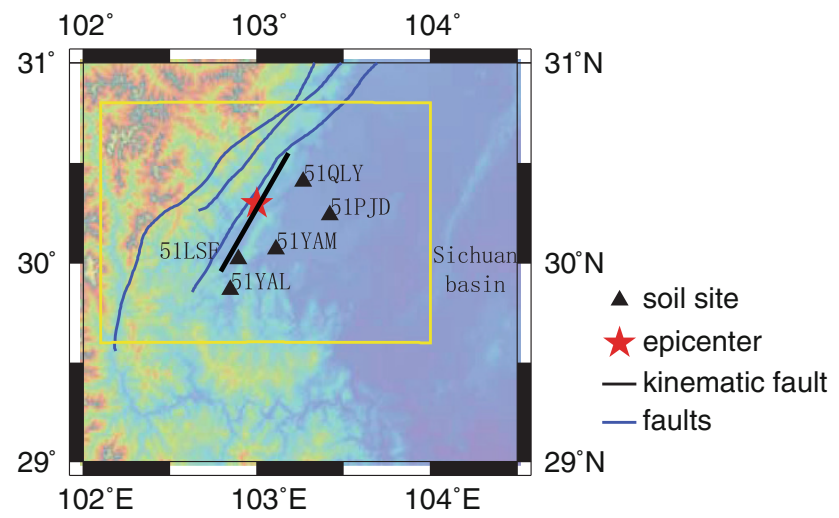

Fig. 1 Map of the stations and faults. Star represents the epicenter of Lushan earthquake, black triangular denote soil site stations. The black line is the kinematic fault (Wang et al. 2013). The blue lines are the fault system in Longmenshan area this study, the maximum influence of soil site effect on estimation of $f_{\max }$ is directly assumed to be about $0.5 \mathrm{~Hz}$, and the influence of $Q$ is ignored. Finally, $f_{\max }$ was estimated by fitting Eq. (1) and the acceleration spectrum from each station (Fig. 2). Table 1 shows the results of the best fits to the preprocessed acceleration spectra from these five stations. The error estimation was done in the same way as shown in Wen and Chen's article (2012).

As shown in Table 1, the best-fitted values of $f_{\max }$ for five stations are very close to each other, and the median value of $f_{\max }$ with uncertainty can be estimated as follows, $f_{\max }=9.8 \pm 0.6 \mathrm{~Hz}$.

\section{Discussion and conclusion}

\subsection{The width of cohesive zone inferred from $f_{\max }$}

According to Papageorgiou and Aki (1983), $f_{\max }$ can be estimated by the following formula:

$f_{\max }=V / L$

where $V$ is the propagating velocity of rupture front, and $L$ is the cohesive zone width which is essential for exciting the seismic waves with frequencies higher than $f_{\max }$. According to kinematic inversion studies (Zhang et al. 2013; Wang et al. 2013), the average rupture velocity is about $2 \mathrm{~km} / \mathrm{s}$. Therefore, the cohesive zone width of the ruptured fault during the Lushan earthquake can be inferred from the formula (2). Since the ruptured fault of the Lushan earthquake has a very limited dimension along strike compared with the Wenchuan earthquake, i.e., 25 versus $300 \mathrm{~km}$, the variations of $f_{\max }$ and the inferred cohesive zone width at these five stations along the fault are very similar. Therefore, we can conclude that the Lushan earthquake has a uniform cohesive zone and its width, $L$, is about

$L=204 \pm 13 \mathrm{~m}$

On the contrary, the Wenchuan earthquake produced a quite heterogeneous distribution of cohesive zone width along the fault as observed by Wen and Chen (2012). Such difference may reflect the difference of earthquake rupture dynamics.

\subsection{Width of cohesive zone versus width of the fault zone}

As shown in the previous section, cohesive zone width of the ruptured fault could be inferred from $f_{\max }$ based on the Papageorgiou and Aki's source-cause model for $f_{\max }$ (1983). We demonstrated in a recent study on Wenchuan earthquake (Wen and Chen 2012) that cohesive zone width of a ruptured fault inferred from $f_{\max }$ is about the same as fault-zone width, and hence they are essentially the same thing. As 

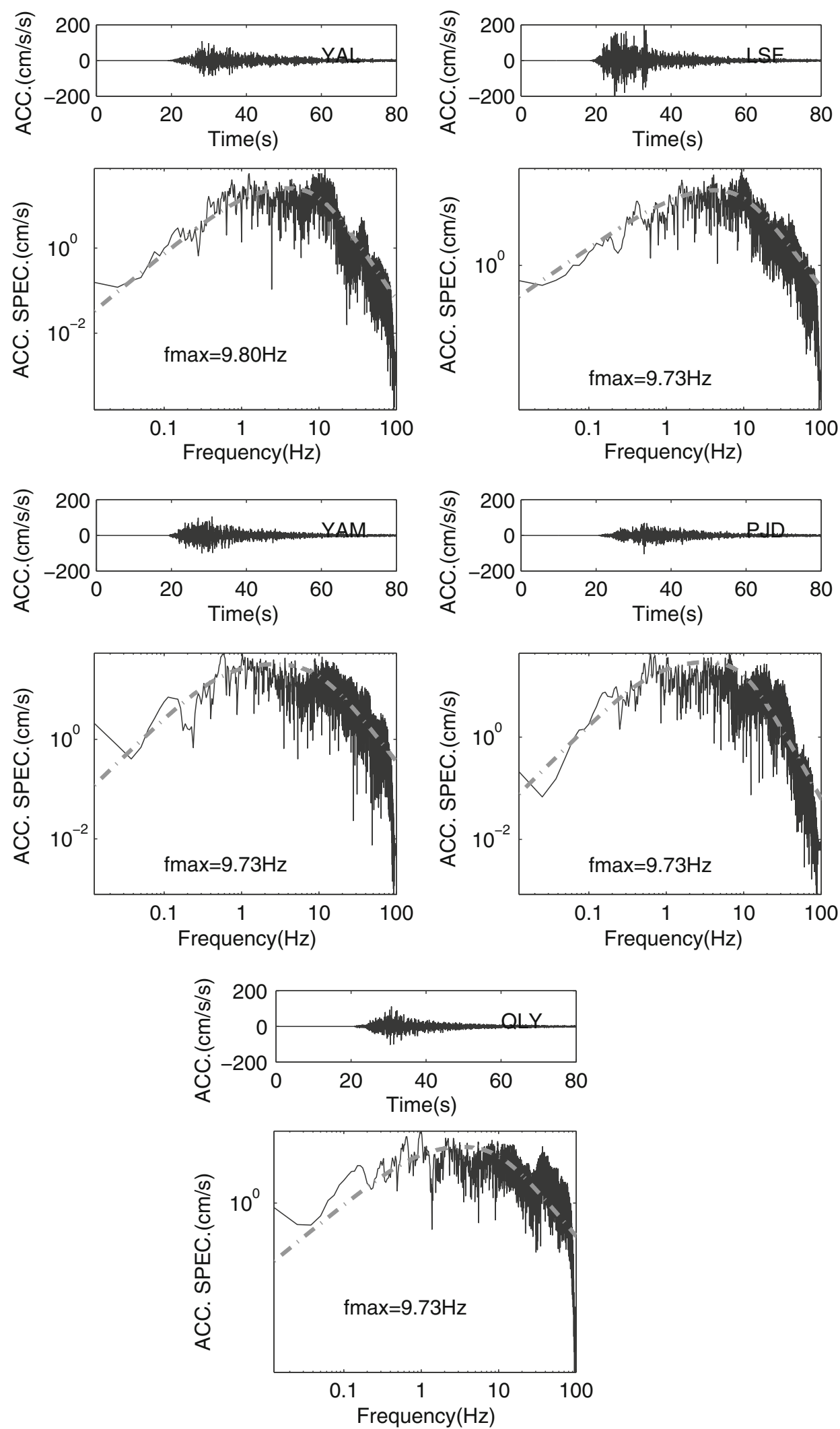

Fig. 2 The accelerograms and spectra of the Lushan earthquake recorded at the 5 stations near the ruptured fault. The dash-dot lines are the best fitting curves to the $f_{\max }$ model given by formula (1), and the values of $f_{\max }$ are the results of best fitting 
Table 1 Best fitted parameters for accelerograms of 5 stations

\begin{tabular}{lccc}
\hline Station code & $f_{\text {max }}(\mathrm{Hz})$ & $p_{\text {high }}$ & amp \\
\hline 51YAL & $9.9 \pm 0.6$ & 2.5 & 32.4 \\
51LSF & $9.7 \pm 0.6$ & 2.0 & 69.4 \\
51YAM & $9.7 \pm 0.6$ & 2.0 & 38.1 \\
51PJD & $9.7 \pm 0.6$ & 2.8 & 33.9 \\
51QLY & $10.1 \pm 0.6$ & 2.8 & 27.6 \\
\hline
\end{tabular}

shown above, the values of $L$ inferred from $f_{\max }$ of Lushan earthquake are $204 \pm 13 \mathrm{~m}$-once again about the same value as the fault-zone width observed elsewhere through fault zone trapped waves field experiments (e.g., Lai and Li 2009; Leary and Ben-zion 1992; Li et al. 1994; Li and Leary 1990; Liu et al. 2004), and this result further confirms that the two concepts are equivalent. It should be emphasized that the measurement of $f_{\max }$ from the observed accelerograms, and consequently inferring fault-zone width, does not require surface exposure of the ruptured fault as long as near-field accelerograms are available. On the contrary, the field experimental method of trapped waves only works when a fault is exposed at the surface.

\subsection{Site effect due to the sentimental soil layer}

Looking back at the spectral amplitudes of the accelerograms shown in Fig. 2, we can see significant bulges
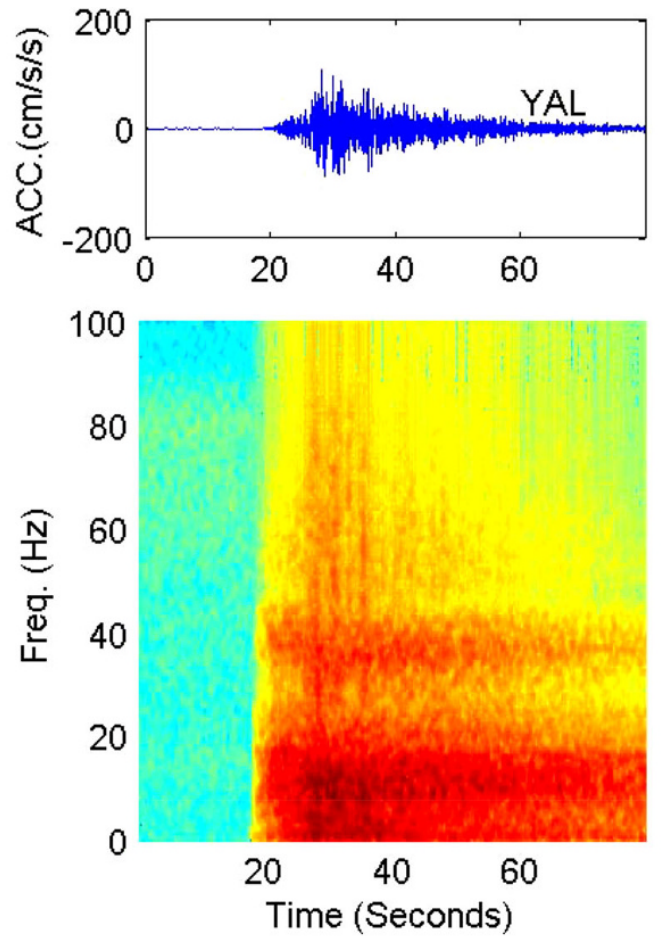

between 30 and $45 \mathrm{~Hz}$ in the double logarithmic coordinates for stations, 51YAL and 51QLY. To understand these bulges, we calculate the time-frequency spectra for the two stations using short-time Fourier transform (STFT). Our results show that for both stations, there is a relatively strong energy band in $30-45 \mathrm{~Hz}$ range almost at all times after S-wave arrival (Fig. 3). Because station 51QLY, with similar distances from the ruptured faults of the Wenchuan earthquake and from the Lushan earthquake, recorded accelerograms for both earthquakes, we compute spectra of the accelerograms from both the earthquakes. As shown in Fig. 4, both spectra show a fairly similar pattern in the band range of $25-50 \mathrm{~Hz}$, i.e., showing a peak at about $37 \mathrm{~Hz}$. This peak frequency is obviously due to site effect at the seismography station, because the two earthquakes, especially their source processes are totally different. This peak frequency can be attributed to reverberation of sedimentary soil layer beneath the station. Similar conclusion can be reasonably drawn to the observed bulge in the amplitude spectra between 30 and $45 \mathrm{~Hz}$ at station 51YAL.

\section{$3.4 f_{\max }$ and fault-zone width versus the rupture process}

Although for big earthquakes, fault rupture usually extends to hundreds of kilometers, it is hard to imagine that the cohesive zone width of such long rupture is uniform everywhere. This is what we have observed in the $M_{\mathrm{w}} 7.9$
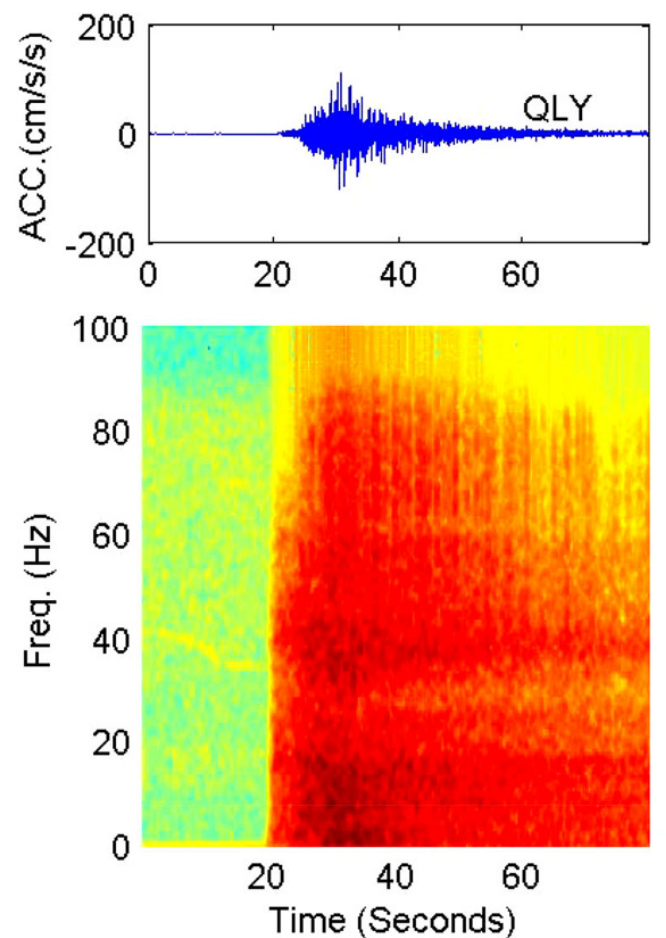

Fig. 3 The accelerograms and time-frequency spectra of stations YAL and QLY. A significant peak energy in the frequency range between 30 to $45 \mathrm{~Hz}$ at almost all time can be observed at station 


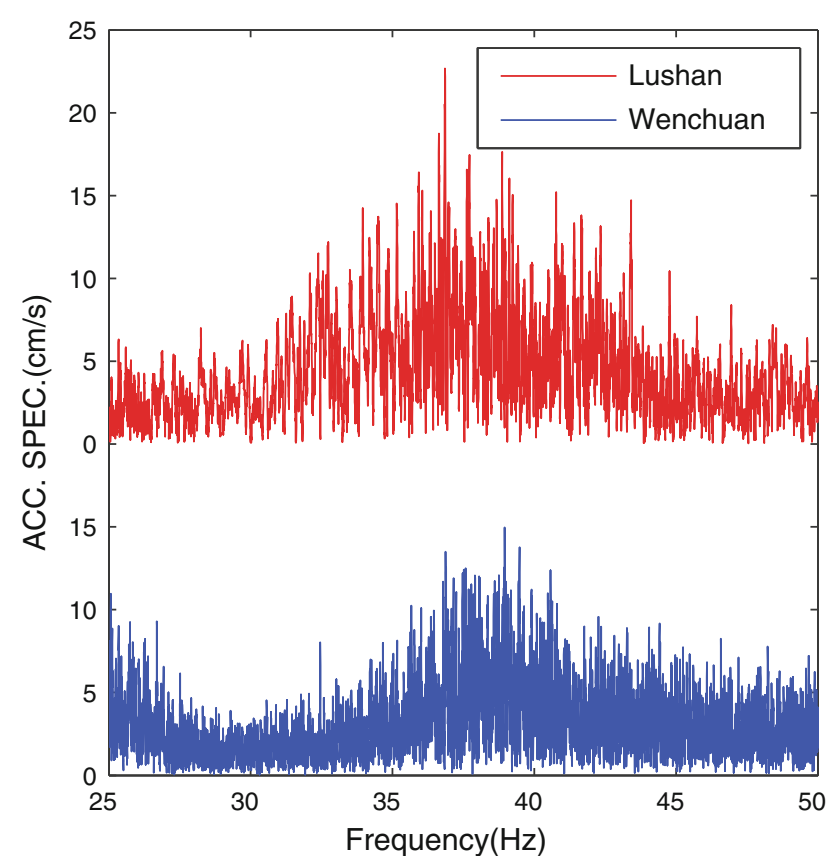

Fig. 4 Comparison of the spectra of accelerograms recorded at station 51QLY for Lushan and Wenchuan earthquakes

Wenchuan earthquake (Wen and Chen 2012). For an earthquake with rupture length much less than a $100 \mathrm{~km}$, the variation of fault-zone width is usually negligible. This is what we have seen from our study on the Lushan earthquake, a uniform fault-zone width. Moreover, studies of seismic source for the Wenchuan earthquake and the Lushan earthquake indicated that the rupture process of the former is very complicated, whereas that of the latter is rather simple (e.g., Zhang et al. 2013). From the standpoint of the source-cause model of $f_{\max }$ (Papageorgiou and Aki 1983), such correlation between the variations in cohesive zone width and rupture process is natural and understandable.

In summary, our study shows that $f_{\max }$ obtained from near-field accelerograms is fairly uniform over the whole fault rupture of the Lushan earthquake, implying that its rupture process is relatively simple. The inferred fault-zone width is uniform and is about $204 \mathrm{~m}$.

Acknowledgments The authors would like to thank Dr. Yong Zhang and Dr. Weimin Wang for providing us their rupture models of the Lushan earthquake. The accelerograms used in this study were provided by China Strong Motion Networks Center (CSMNC). This study was supported by the National Nature Science Foundation of China (Grant numbers: 41090293, 41274053).

\section{References}

Lai XL, Li SL (2009) Observation of fault zone trapped waves in Wenchuan earthquake region, earthquake research in Sichuan, 2009. 3:8-11

Leary P, Ben-Zion Y (1992) A 200 m wide fault zone low velocity layer on the San Andreas fault at Parkfield: results from analytic waveform fits to trapped wave groups. Seism Res Lett 63(1):62

Li YG, Leary P (1990) Fault zone seismic trapped waves. Bull Seism Soc Am 80:1245-1271

Li YG, Aki K, Admas D et al (1994) Seismic guided waves trapped in the fault zone of the Landers, California, earthquake of 1992. J Geophys Res 99(B6):11705-11727

Liu MJ, Li SL, Zhang XK et al (2004) Haiyuan fault zone fault zone trapped wave width of the shattered zone fine structure. Geophys Geochem Explor 28(6):549-552

Papageorgiou AS (1988) On two characteristic frequencies of acceleration spectra: patch corner frequency and $f_{\max }$. Bull Seism Soc Am 78:509-529

Papageorgiou AS, Aki K (1983) A specific barrier model for the quantitative description of inhomogeneous faulting and the prediction of strong ground motion. Part I description of the model. Bull Seism Soc Am 73:693-722

Wang WM, Hao JL, Yao ZX (2013) Preliminary results for rupture process of April 20, 2013, Lushan earthquake, Sichuan, China. Chin J Geophys 56(4):1412-1417

Wen J, Chen XF (2012) Variations in $f_{\max }$ along the ruptured fault during the $M_{\mathrm{w}} 7.9$ Wenchuan earthquake of 12 May 2008. Bull Seism Soc Am 102:991-998

Xu XW, Chen GH, Yu GH et al (2013) Seismogenic structure of Lushan earthquake and its relation with Wenchuan earthquake. Earth Sci Front 20(3):11-20

Zhang Y, Xu LS, Chen YT (2013) Rupture process of Lushan 4.2 earthquake and preliminary analysis on disaster-causing mechanism. Chin J Geophys 56(4):1408-1411 